\title{
Re-writing the University with 'Reading the Country'
}

\section{Katrina Schlunke}

I loved the aim of the festival that was Reading the Country; Thirty Years On. 'The festival aims to revisit and recapture the intellectual radicalism and political energy of that time', the invitation read. 'That time' was 1984, the year of the original publication of Reading the Country. The festival, not conference, asked we participants to 'consider the multi-faceted aspects of the text and re-read it in light of changes in Australian society and universities, and contemporary developments in critical theory and reading methods'. But 1984 does not stand out for me as a year of 'radicalism' or 'political energy'.

As a first-year student at Melbourne University in 1984 I found a university culture that had just turned from a popular concern with Pine Gap to a popular concern with chocolate and Christianity in the guise of the vote-grabbing Chocolate Appreciation Society and the highly active and influential Christians on Campus group. I was in a university college where it was assumed a country high school girl would be safe under the wing of its Presbyterian antecedents but where my O'Week was spent drinking heavily, really very heavily, and calling out to each other college in turn: 'Trinity takes it up the arse', 'Queens fuck goats' and 'All Catholics are cunts'. This final one was a particular problem to me given that I had a) never used the term 'cunt' before; b) I knew a chunk of my family had been Catholic until the romantic tragedy of my grandparents marrying across the Anglican-Catholic divide threw future generations into Presbyterianism and, more generally, Catholicism was related in my mind to culture and civility via the piano teaching nuns of my town; and c) I had just returned from a year of exchange in Mexico where 
everyone I loved was Catholic and where I myself had seamlessly taken to crossing myself upon all sorts of occasions. Apart from these outward efforts at abuse, we college 'freshers' also participated in a variety of collective humiliations in the name of exorcising pre-existing ties between those students who had all come from similar privates schools and replacing it with new ones based on collegial fraternity that would include folk like myself who had come from somewhere else entirely. In its pared down tribal primitivism these rituals were radical but not exactly politically energised as imagined by the Reading the Country, 30 Years On festival organisers.

But the 1984 campus/college environment also boasted reading groups, junior common room debates about issues of the day and collective subscriptions to a wide variety of newspapers and literary reviews. And the university, even amid the turn to God and chocolate, still had the Student Union-supported clubs and societies that included Judy's Punch, the feminist collective, and an active political life that included going onto the streets and into the offices of the university hierarchy. It was only a few years later that we would be organising the first demonstration against the introduction of fees-in 1986 I think-where we occupied the Stock Exchange in what now seems a very prescient understanding of what was happening to us.

What I remember as an oasis of that time was the Koori Centre run by Lisa Bellear. Or maybe someone else was running it but Lisa was definitely the force and that was where the arts, politics and fun, joy actually, really came together in a way that you could feel if not quite articulate at the time. And if there is some inchoate model of an ideal space from the mid 1980 s that would be it for me. So this jumble of joy and political losses amid an assumption about what would last within a university culture is my lightly strung temporal bridge from my 1984 to Reading the Country. Before the festival I had never linked Reading the Country to the time it was written. Reading the Country is associated in my mind with the excitement of cultural studies and the real pleasures of learning to read again at the University of Western Sydney after I left Melbourne Uni. So I thought I would write a reflective piece on why for all sorts of reasons associated with curriculum and culture I could 
not 'read' Reading the Country in my very first encounter with it. But doing that felt a little like squandering the legacy of the book and its accumulated and accumulating force.

So this is instead some writing about not reading the book Reading the Country, but rather treating it like a 'working vehicle', as a ute that might take you round corners so you have to hang on for dear life or as a really good ride that you can enjoy like a happy kelpie with your tongue hanging out in the wind, trusting the book and the words and ideas within it will get you somewhere. Somewhere unexpected.

For me at the moment, universities are small places. They have shrunk even as they build more and more buildings and make campuses further and further from this country. They are not the rich places supported by knowledge and elders and community like the Fitzroy River community that Anne Poelina and others are growing because they know a visit there might grow all of us up. ${ }^{1}$ They are, as Philip Morrissey suggests, places that need the restorative practices represented by Paddy Roe, of 'respect, sympathy and modesty'.2 But how could I bring these two worlds of thinking together? These two worlds that don't meet? My method is to begin with some little fragments of these Lilliputian worlds, an email and a piece of policy, but use the tactics bequeathed to us in words and method by Paddy Roe and Stephen Muecke to rethink them. So I am not 'reading' Reading the Country, I am more bluntly using it. At least some of the time, in some of the places we call universities, research and teaching are still the heart of what we do even if doing that might now be called 'core business', so it is through those headings that I begin to re-read.

\section{Re-reading research and teaching Research}

This is what research looked like in Reading the Country. This is the sound of Stephen listening, conducting research, on pages 35 to 46 :

$\mathrm{Mm}$,

No?

Oh right

Yeah. 
What's this one?

Yeah

Yeah

Is that cattle truck there?

Got big foot that one

Oh yeah brahman

Right

You used to make things with that, clay?

You used to make em?

Oh right

Yeah

This is the sound of research, communicated via a general email to staff in a faculty of an Australian university:

As a starting point for working out the future of the Strengths, Centres, Programs and Networks I would now like your suggestions in two categories:

1. Areas where we could make a defensible claim, right now, that 'In the area of XXXX, the best research in the country is being conducted at (name of university)'. Can you also please send me the names of the key (name of university) researchers working in this area.

2. Areas that are emerging and where you think that, in three years' time, we could make a defensible claim that 'In the area of XXXX, the best research in the country is being conducted at (name of university)'. Can you also please send the names of the key (name of university) researchers in this area, and your suggestions about what we would need to do in the next three years in order to make us the best in Australia? ${ }^{3}$

\section{Teaching}

Paddy Roe on teaching:

That's why we can't teach young people this time we put lotta things away from these fellas because today too much drink in the road no good for young people they can't use-im right way ${ }^{4}$ 
and later...

If we only just

teach

just tell-im stories

stories

you know just tell-im stories

just tell-im stories

if we tell-im stories but they won't work for-im

and later...

They like to see it they like to see it move,

but er sometime they tell us

'Why don't you people make it move?' you know so we can see

'Yes, but er our old people didn't teach us how to move these things so we can't move-em (Laugh) we can only tell you story (Laugh)

And this is the description of teaching to be that was circulated at an Australian university in 2014. It was concerned with approaches to teaching and included the following:

It has been agreed that a university KPI be developed that measures the university's adoption of [name of program]. This will require:

i. Agreement on the conditions under which a subject/ course is certified as '[name of program] compliant' (see Appendix A for draft)

ii. Establishment of a system of peer review of compliance

and under 'Supporting Students':

Students (will be) given a 'flipped task' to Google themselves before arrival, and in session discuss the pros and cons of their online identity. 
Professional Identity Photo Booths (will) provide opportunities for students to be photographed in professional themed costumes as well as corporate attire for future use in (their) online profile development ${ }^{5}$

To gloss and simplify the differences we could say Stephen's style of research in the quoted instance was based upon listening and the university's is based upon competition, being the 'best of the best'. In terms of teaching, Paddy Roe suggests that the student must be ready, that not everyone or everything should be taught and that important stories, important knowledges should be kept from those who aren't ready for them. He also seems to be saying that what we teach is limited by what we were taught and that there is a connection between those ancestors who made the world, 'moved things' and the stories we tell now. In its current shape teaching in university bears no relationship to the Indigenous forces that made our world. The limits to knowing university knowledge are shaped by financial issues and as teachers where flexibility of delivery trumps content, we are often teaching what we have not been taught, including, I assume in the future, how to dress our students in 'corporate attire'.

But even this short comparison drains something away from what was happening when Stephen listened and Paddy Roe spoke. We've lost the country itself and we've lost the context and the power of the multiple politics happening in those moments they are together. So I am not suggesting we should simply make a model of research and teaching whereby we would list the characteristics of ideal research and learning situations that would include Listening, Student Readiness and Teachers teaching only what they have been taught or have the right to know (although that could be a step in a good direction). For if we shape one situation, even one as attuned to both the poetics and politics of its moment as Reading the Country is, into a model that can be applied anywhere, anytime and is enforced by an institution and measured, then the specificity of that practice is drained of its vitality, its infectiousness and its ineffability. That I think would be a critical abuse of Reading the Country. And using other people's work is something that needs to be done well, as in with respect, 
because Paddy Roe is not here to be asked 'Can I use your words over here?' Stephen is here but it isn't only Stephen's words I want to use - it is both of them, together. And this brings us to a confrontation with the ethics of the recorded word, translated onto the page and circulated to decontextualised others. As Ross Gibson (and others) wrote a very long time ago but neatly emphasised via Ong in South by South West, the act of translating local knowledge to transportable readable documents was one of the conditions of possibility that allowed colonisation. ${ }^{6}$ Reading the Country was created in a particular shape to precisely challenge that kind of colonial transformation of orally imparted knowledge. It's very hard to turn Paddy Roe's words into the language of military coordinates, of places, distances and boundaries. And I think (although I am not certain) that writing up Paddy Roe's words in their heard rhythm so we take in his laughter and the gaps between words that emerge out of Stephen's style of listening and then using all of that affecting exchange to reconfigure ordinary university talk would help me. It would help me grow the 'small' university. It might also make a little path between the colonising university (colonised and colonising by capital and 'management' of Indigenous and non-Indigenous knowledges) and what Paddy Roe and Stephen say and do. The first path is poetry of a sort, a simple verbal experiment:

\title{
The Professional Identity Booth
}

\author{
Professional Identity Photo Booths \\ (will) provide \\ opportunities for students to be photographed \\ in professional themed costumes as well as corporate attire \\ for future use in (their) online profile development \\ $\mathrm{Mm}$, \\ No? \\ Oh right \\ Yeah. \\ What's this one? \\ Yeah \\ Yeah \\ Right
}


Can you also please

send the names

of the key (name of university) researchers in this area

and your suggestions about

what we would need to do

in the next three years

in order to make us the best in Australia?

$\mathrm{Mm}$,

No?

Oh right

Yeah.

What's this one?

Yeah

Yeah

Right

As Paddy Roe says:

our old people didn't teach us how to move these things so we can't move-em (Laugh) we can only tell you story (Laugh)

\section{Only stories}

That extracted phrase of Paddy Roe's keeps me thinking: 'our old people didn't teach us how to move these things so we can't move-em (Laugh) we can only tell you story (Laugh)'.

Moving his words through the claims that the university will help students by assisting them in the performance of 'professionalism' without reflecting on the formation of those trappings of corporate life and efforts to pick out only the 'best' of researchers without considering their context sets up a resonance with how we, me, all of us who have moved through the university system were taught to 'move' things. If I have understood the context correctly Paddy Roe is talking about the literal making of the land, the creative power of those early ancestors and how that power was not passed on but the stories were. But those stories still carry some current that will change things in unexpected ways. In the putting on of professional costumes and picking and personalising 'the best' researchers there is no preceding act of vast creation. These 'stories' of the university are denuded of any complex time and work like bullets, only one trajectory imagined: forward, 
into and onto bodies. So asking over and over again, 'what are these stories' lets us potentially see that they don't necessarily belong to the acts of teaching and research. The stories of being the best, of dressing up as professionals, do not come from a complex time of creation. They are concrete actions denying the moving creativity of research and teaching. Paddy Roe's technique of discernment could be best summed up as: What's this one? So if we can see with Paddy Roe's help that these stories don't last, don't belong, what stories do? Here is another story.

\section{Following and reproducing out west}

Here's a story about driving in a car. It's a Lexus actually. I think of it as Pru's car because she loves driving. She will drive places when everyone else in the city has given up and decided they can only get there by bus or walking. ${ }^{7}$ It has seat warmers. But today Stephen is driving, is driving me in fact. And we are not, as the Lexus might suggest, anywhere near Broome or up north although we are headed west. We are going out to meet up with, talk with, the Western Sydney University FictoLab at Parramatta. They are, we are, contertulios. ${ }^{8}$ That is, we are participants in a tertulia inspired event. What is a tertulia? Wikipedia will tell you it is:

rather similar to a salon, but a typical tertulia in recent centuries has been a regularly scheduled event in a public place such as a bar, although some tertulias are held in more private spaces, such as someone's living room. Participants, known as contertulios, may share their recent creations such as poetry, short stories, other writings, and even artwork or songs. ${ }^{9}$

The UWS postgraduates have created a different form whereby they invite different fictocritical guests to join them after their fictocritical workshops to have a chat and a tea and/or drink. Today it will be a drink as we are meeting at a pub, the Albion. Stephen is worried. His son Joe and partner Nana are having a baby and Nana (the mother to be) has gone into hospital with complications in Denmark where they live. Everyone is waiting for news. It will be Stephen's first grandchild. 
We move with the flow of traffic and so start out fastish and then slow to the stopping start pattern of the choked up M4 motorway. Although we were invited to the University of Western Sydney only a few weeks ago, it has now become the Western Sydney University, reborn via a multimillion-dollar design team to become a little bit different, a little bit the same as before. I like it. As an alumnus I like that we might now reply to the query, 'So where did you go to uni?' with 'Western Sydney'. In that ordinary, mild way, we ex-students will lay claim to a whole history of class, development, neglect, politics, innovation, a history of suburban sprawl and the pulse of an Australia figured upon diversity, that is western Sydney.

We are already on this country of 'Western Sydney' but neither in it or of it. We are driving through the suburbs although we wouldn't really know. We are driving along motorways or highways and only occasionally see homes where people live or open land that might suggest where people once lived. Stephen writes about two ways of producing culture in Reading the Country: "Either one can "reproduce" or one can "follow". The theoretical space which takes as its conditions of operation the constants of gravity and metrics reproduces the same objects continually, mechanically, professionally.' ${ }^{10}$ Stephen is using a bit from Deleuze and Guattari that juxtaposes the mechanicalness of reproduction against the positive suggestion of what might arise from stepping off the bank and jumping into the flow that following suggests. Following, means we don't keep reproducing the same object.

In our car we are surely following. Following the other cars, following the strictly controlled major motorway when we are on that. And in doing so we are reproducing ourselves each kilometre passed, as the same cultural object: commuter, user of cars, human wiping our tyres over earth or animal, anything that we are not protected from or in control of. In this way our 'following' is not what Deleuze and Guattari meant; in sticking to the path made by others in watching the houses flow by we are not really 'following' at all merely reproducing one kilometre after another of what is already there.

But in another sense we are following. We don't know what this fictocritical group might have done today; in saying yes to this invitation we are also throwing ourselves into a flow 
that will take us somewhere we have never been physically or intellectually. An open invitation is a current to be swept into, to join with. In Reading the Country Stephen quickly leaps from Deleuze and Guattari to examples from Indigenous life and Paddy Roe including examples of what it means to track. Through 'tracking up' the tracker comes to know place and person. To walk exactly in their footsteps means that there is an imitation - not a reproduction - of the whole movement of their bodies.

In following the connective maps of the UWS mob who are becoming the Western Sydney mob I am not so precise. But I do want to imitate their model. By putting my body in the spaces and traces left by theirs I too could create an eddy and flow for others to follow. But here we have to think about time and context and the knowledge that what they are doing is connected to something that others have done, other academics, other thinkers and other writers who in their teaching and in their research created connections, pointed out flows that others could follow. In universities it was and sometimes still is, called a 'research culture', but it can also be a salon, a reading group, a writing group or a drink with curious folk. In a very different way to what is at stake for Paddy Roe in the appropriate people knowing how to know his land, these currents created by these small groups that we jump into are also vulnerable places. Vulnerable to being mined out via the requirement to reproduce accounts of why we met, whether or not we had spent money and what we might produce as 'outcomes' in the future. To limit the demand of that audit fracking the most energetic of these gatherings are simply para-institutional now. Alongside the university but not of it. Using the university to initiate a dialogue but letting whoever will step into the following of where this idea or that group might go. These gatherings are more open to diverse communities and less likely to be as they once would have been, an assumed part of a university department culture. Like some highly affective and infectious being these little groups come and go, grow and die and are reborn, somewhere else, sometimes looking very different.

I like the idea of affective imitation Stephen evokes through his description of one of us putting our feet exactly in the 
imprint of another. Yes, it is an imitation of the stance of the body of that individual as we model the pad of our foot to exactly that angle and yes it is a learning to walk like another with others. But it also means one singular path is made over land. One path unable to be shared by too many others. One person has earned the right to make that path in that way and to initiate an imitative following. This idea of strengthening the particularity, the unpredictable currents and eddies of one body when applied to a 'body' of ideas interests me. In following the Western Sydney Ficto Mob out here, out to the Albion in Parramatta, I am accentuating the effects of their intellectual marks while adding my own that may eventually be felt by another. These are the lines of fight for the kind of thinking that travels with the past and future and discerns in the present what belongs to the generative possibilities of this moment.

We arrive at our destination. We know we are there before we are actually there because the chosen voice of Google Maps tells us so. Stephen checks his phone and discovers that in that fortyfive-minute, all-road-bitumen and car-all-the way space speckled with conversation and revelation, gossip and silence he has become a grandfather. There is delight. All the way over there to all the way here has come status-changing news. Is the birth of a baby reproduction, or following? Perhaps a little of both.

We go into the Albion. The Albion is kind of famous and has a past. In 2013 shots were fired into the car park and the hotel itself in the early morning when the pub was still populated by drinkers. As the policeman said at the time: 'By the Grace of God no-one was injured.' This evocation of divine forces seemed apt given the description that the pub was a 'known hangout of the Hell's Angels outlaw motorcycle gang'. The incident was to be investigated with the help of Operation Apollo targeting 'gun and organized crime'. ${ }^{11}$ In another incident in 2012, police had been pushed, punched and spat upon in an incident also involving the Hell's Angels. ${ }^{12}$ This pub has been in place since 1860 and accounts of bad behaviour at the Albion go way back. In 1928, for example, a constable told two men who were drunk and wanted to fight each other to 'go home'. They don't and get arrested and there is a court case where one of the men denied he ever wanted to fight in an exchange that was reported verbatim: 
'Fight's the thing I never look for.'

'You're one of the Rydalmere Burkes aren't you?'

'I am.'

'And you don't know how to fight?'

'No.'

But the court ruled: 'The constable was perfectly right in trying to send these men home and in issuing a summons when they persisted in their riotous conduct. ${ }^{13}$ Where do academics fit with outlaws and angels? A bit of both? In meeting at the Albion are we following older histories of trouble and troublemaking?

The Albion opens wide, inviting us into its beer garden and social spaces marked by cosy corners, veranda style pavilions and long tables reserved for trivia. And it follows a temporal logic geared towards early morning, opening until 4:00 am. Maybe this is why Operation Apollo had some success here. Apollo who moved the sun across the sky. The old god of the late night opener? This is a good place to think with. It has curved seating around tables and it spreads out for serious drinkers and then curls in for those of us wanting group conversation. We follow the prompts. We toast Stephen becoming Lulu, although not exactly Lulu. Paddy Roe's Lulu is, as I understand it, a precise connection, naming lawful relations. Our toast is an affectionate muddle of wonder, sentiment, hazy memories of Grannies and Grandpas and thoughts about how to name aging. The toast is an enactment between the Albion and us and an idea of what we might be and what Stephen may become. Re-reading is now also re-enacting 'family'. We use sensations and material resources from multiple times to trouble an assumption of what a university now is and who we are as higher education affiliated folk met and made by the Albion. And Paddy Roe.

In our particular expression of what we wished to do, in the enactment of something both traditional and new, we have territorialised the Albion, the spaces between here and the city, those between western Sydney and eastern Sydney and between loosely formulated disciplines. In our expression of being there we were not defensive but talkative. We were neither the best of the best nor easily recognised in our de rigeur professional costumes. In the right light we might have 
been mistaken for a trivia team or an after work party, which I think would have suited us fine. We were connected to rather than distinct from our place, using the old pub, each other, the tradition of meeting and talking, to 'follow the flux of matter that keeps one alive'. ${ }^{4}$ To have been given some clues on how to find that conditional and contingent liveliness in the university, in this time, across space, right now and right then is a legacy of Reading the Country. Or maybe more than a legacy - it's a kind of law about how to survive. Listen. Repeat stories. Follow the flux of matter.

\section{Notes}

1 Anne Poelina, presentation to the Re-reading the Country Festival, December 2016.

2 Philip Morrissey, presentation to the Re-reading the Country Festival, December 2016.

3 Although this was a specific email at a specific institution it is typical rather than particular. It is perhaps cruder than some institutional approaches but possibly smoother than others. It is the underlying order of competition and marking shared by both universities and corporations that I am drawing attention to here. Krim Benterrak, Stephen Muecke and Paddy Roe, Reading the Country: Introduction to Nomadology, Fremantle Arts Centre Press, Fremantle, 1984, p. 88. Again, although is a very specific example from a specific institution it is its typicality rather than specificity I am highlighting here. Its language of ' $\mathrm{flipped}$ learning' and unquestioning 'professionalism' is a very usual focus in many institutions.

6 Ross Gibson, South of the West: Postcolonialism and the Narrative Construction of Australia. Indiana University Press, Bloomington, 1992, p. 4.

7 I refer here to Dr Prudence Black, author of The Flight Attendant's Shoe (New South, Sydney, 2011), also Stephen Muecke's partner and co-owner of the Lexus.

8 With many thanks to Hermann Ruiz for organising this event and our fellow thinkers and readers, including Alex Coleman, Jasbeer Mamalipurath, Tsvetelina Hristova and Christiane Küling.

9 'Tertulia', Wikipedia, <https://en.wikipedia.org/wiki/Tertulia>.

10 Benterrak, Muecke and Roe, p. 248.

11 Di Bartok, 'Shots Fired into Albion Hotel', Daily Telegraph, 15 February 2013 pp. 1-3, <https:/www.dailytelegraph.com.au/newslocal/parramatta/shots-fired-intothe-albion-hotel-at-245am-believed-to-be-gang-related/news-story/63f23b4141f113 df34905ffgebf3496o>.

12 'Four Bikies Charged over Parramatta Brawl and Shooting', The Sun, Parramatta and Holroyd, 17 July 2012, http://www.parramattasun.com.au/story/249313/ four-bikies-charged-over-parramatta-brawl-and-shooting

13 The Cumberland Argus and Fruitgrowers Advocate, Thursday 7 February 1928, http://nla.gov.au/nla.news-article104717065.

14 Benterrak, Muecke and Roe, p. 246. 